\title{
Relationship between Helicobacter pylori and thiol-disulfide homeostasis: A prospective observational study
}

\section{Helicobacter pylori ve tiyol-disülfid homeostazı arasındaki ilişki: Prospektif, gözlemsel bir çalışma}

\author{
Umut Eren Erdoğdu ${ }^{1}$, Hacı Murat Çaycı ${ }^{1}$, Ali Tardu ${ }^{1}$, Ufuk Arslan ${ }^{1}$, Yasemin Budak ${ }^{2}$, Özcan Erel ${ }^{3}$, Hakan \\ Demirci $^{4}$, Hasan Cantay ${ }^{5}$
}

\section{Abstract}

Aim: Helicobacter pylori (HP) infection causes inflammation and oxidative stress at a cellular level. In the present study, we aimed to evaluate the possible relationship between HP and thiol-disulfide homeostasis (TDH), a novel indicator of oxidative stress.

Methods: Medical data of a total of 53 patients admitted with persistent dyspepsia and undergoing gastroscopy were evaluated prospectively. The patients were divided into two groups, based on the result of gastric biopsy, as HP-positive (+) and HP-negative (-). Demographic data, ferric-reducing ability of plasma (FRAP), ischemiamodified albumin (IMA), native thiol, total thiol, disulfide, and malondialdehyde (MDA) levels of the patients were recorded and compared between the two groups.

Results: The native thiol $(451.03 \mathrm{mmol} / \mathrm{L}$ vs. $407.03 \mathrm{mmol} / \mathrm{L}, \mathrm{p}=0.005)$ and total thiol $(493.20 \mathrm{mmol} / \mathrm{L} \mathrm{vs}$. $456.40 \mathrm{mmol} / \mathrm{L}, \mathrm{p}=0.027)$ levels were significantly higher in the HP (+) group than in the HP (-) group. The disulfide levels and disulfide/native thiol, disulfide/total thiol and native thiol/total thiol ratios were similar between the HP (+) and HP (-) groups. Although the FRAP was lower in the HP (+) group than in the HP (-) group, this difference was not statistically significant $(0.94 \mathrm{mmol} / \mathrm{L} \mathrm{vs} .1 .10 \mathrm{mmol} / \mathrm{L})$. No statistically significant difference was found between the groups in the IMA and MDA levels..

Conclusion: In this study, oxidative status of HP patients was evaluated in several different methods. Among them, only elevated native thiol and total thiol levels were found in HP-induced gastritis. There is a need for further studies involving a larger number of patients and a subgroup analysis to examine whether elevated serum thiol-disulfide levels in HP infection suggest an antioxidant or pro-oxidant status.

Key words: Helicobacter pylori, homeostasis, thiol, disulfide, oxidative stress
${ }^{1}$ Bursa Yuksek Ihtisas Teaching and Research Hospital, General Surgery Clinic, Bursa, Turkey.

${ }^{2}$ Bursa Yuksek Ihtisas Teaching and Research Hospital, Biochemistry Clinic, Bursa, Turkey.

${ }^{3}$ Yildirim Beyazit University, Department of Biochemistry, Ankara, Turkey.

${ }^{4}$ Bursa Yuksek Ihtisas Teaching and Research Hospital, Family Medicine Clinic, Bursa, Turkey.

${ }^{5}$ Kars Karakani State Hospital, General Syrgery Clinic, Kars, Turkey.

iD

UEE: 0000-000-12-6700-1858

HMC: 0000-0002-4833-1509

AT: 0000-0003-0287-6789

UA: $0000-0002-3050-167 \mathrm{X}$

YB: 0000-0003-2415-0372

OE: 0000-0002-2996-3236

HK: 0000-0003-0434-4807

HC: 0000-0003-3309-8879

Ethics Committee Approval: The study was approved by Bursa Yuksek Ihtisas Teaching and Research Hospital (2011-KAEK-25; 2018/06-06; 20.06.2018).

Etik Kurul Onayı: Çalışma Bursa Yüksek İhtisas Eğitim ve Araştırma Hastanesi tarafindan onaylanmıştır (2011-KAEK-25; 2018/06-06 20.06.2018).

Conflict of Interest: No conflict of interest was declared by the authors.

Çıkar Çatışması: Yazar çıkar çatışması bildirmemiştir.

Financial Disclosure: The authors declared that this study has received no financial support.

Finansal Destek: Yazarlar bu çalıșma için finansal destek almadıklarını beyan etmişlerdir.

Geliş Tarihi / Received: 21.09.2019 Kabul Tarihi / Accepted: 11.04.2020

Yayın Tarihi / Published: 31.08 .2020

Sorumlu yazar / Corresponding author:

Umut Eren Erdoğdu

Adres/Address: Bursa Yuksek Ihtisas Egitim ve Arastırma Hastanesi Genel Cerrahi Kliniği, Mimar Sinan Mah. Emniyet Caddesi, Yildirim, 16310, Bursa, Turkey.

e-posta: umuterdogdu @ gmail.com

Tel/Phone: +90 5337331208

Copyright (C) ACEM 


\section{Introduction}

Helicobacter Pylori (HP) is a spiral gram-negative, microaerophilic bacterium, highly adapted, that selectively colonizes the human stomach [1]. It is transmitted by fecal-oral, gastro-oral and oral-oral routes, assuming that the infection is mainly in childhood. According to statistics, it affects around 3-4 billion people worldwide, with the rate of infection in developing countries very high, reaching up to $80 \%$ [2]. During the host colonization process, HP induces a strong inflammatory response, characterized histologically by superficial epithelial degeneration and infiltration of the gastric mucosa by inflammatory cells [3].

$\mathrm{HP}$ results in reactive oxygen species (ROS) and reactive nitrogen species (RNS) production from the gastric mucosa. Low and moderate amounts of ROS have a beneficial effect on several physiological processes including the killing of invading pathogens, wound healing and tissue regeneration processes [4]. Although immune system is capable of creating an immune response to the infection, it usually fails to clear HP. The inability of the host to clear HP results in a chronic inflammation with continued oxidative stress within the gastric tissue. Determination of oxidative stress in gastric inflammation may be necessary for a better understanding of its pathophysiology [5].

Oxidative stress plays an important role in the pathogenesis of inflammation, the level of which is measured based on such parameters as FRAP, IMA, MDA, and thioldisulfide

[6-9]. Moreover, a relationship between oxidative stress and the development of HP infection has been demonstrated in many studies [5, 10-12]. Elevated serum thiol-disulfide levels can be seen under conditions with increased oxidative stress such as HP-induced gastritis. In the present study, we aimed to evaluate the possible relationship between HP and thiol-disulfide homeostasis, a novel indicator of oxidative stress.

\section{Material and methods}

Medical data of a total of 53 patients who were admitted to hospital between April 2018 and June 2018 with persistent dyspepsia, and had undergone gastroscopy, were evaluated prospectively. Detailed information about the procedure and study was supplied to all patients and written informed consent was obtained. The study protocol was approved by the local Ethics Committee. The study was conducted in accordance with the principles of the Declaration of Helsinki. Ethical approval was obtained from the hospital's ethical committee (2011KAEK-25 2018/06-06).

\section{Inclusion and Exclusion Criteria}

This study included 53 literate patients with chronic dyspeptic complaints (lasting more than three months), aged between 18 and 70 years, who agreed to participate in the study. Patients with varicose, inflammatory or active ulcerous lesions in the upper gastrointestinal tract that could cause hemorrhage and those with a previous history of gastric surgery were excluded.

\section{Interventions}

Gastroscopic interventions were performed under sedation by a single endoscopist in the endoscopy unit. A biopsy was obtained from four different quadrants in the antral mucosa. difference between the groups $(\mathrm{p}=0.388)$. FRAP was also lower in the HP (+) group, although the difference between the two groups was not statistically significant $(\mathrm{p}=0.059)$. The mean
A 5-mL blood sample was withdrawn into two separate tubes before the gastroscopic intervention, and the samples were centrifuged at 4,000 rpm for $10 \mathrm{~min}$. The sera were stored in the Eppendorf tubes at $-80^{\circ} \mathrm{C}$.

After the measurement of weight and height according to the standard protocol, body mass index (BMI) was calculated using the following formula: BMI $\left(\mathrm{kg} / \mathrm{m}^{2}\right)=$ weight $(\mathrm{kg}) / \mathrm{height}^{2}$ $\left(\mathrm{m}^{2}\right)$. Blood pressure measurements were performed at the outpatient clinics of the general surgery department according to the standard protocol.

\section{Grouping}

The patients were divided into two groups, as 27 patients with HP infection (HP-positive) or 26 patients without HP infection (HP-negative), based on the results of a pathological examination of gastric biopsies. Participants who never smoked were recorded as smoking (-) patients and active smokers were the smoking (+) group.

\section{Outcomes}

Demographic data, the ferric reducing ability of plasma (FRAP), ischemia-modified albumin (IMA), native thiol, total thiol, disulfide, and malondialdehyde (MDA) levels of all patients were recorded. IMA levels were analyzed spectrophotometrically according to the method described by Bar Or et al. [10]. Serum TDH was analyzed by a novel automated method [13]. Total antioxidant capacity (TAC) was measured with the FRAP method which measures all available antioxidants aside from thiols [7].

\section{Statistical Analysis}

Statistical analysis was performed using the Statistical Package for the Social Sciences (SPSS) version 21.0 software (IBM Corp., Armonk, NY, USA). The Shapiro-Wilk test was used to evaluate whether the variables were normally distributed. The data were expressed in mean \pm standard deviation (SD) or median (min-max) and number and frequency. Based on the results of the normality test, either an independent samples t-test or Mann-Whitney U-test was used to compare the groups. The categorical variables were compared using a chi-square test. A binary logistic regression analysis was carried out to examine the independent risk factors affecting the occurrence of HP. A p value of $<0.05$ was considered statistically significant.

\section{Results}

Of the study patients, $28.3 \%$ were males and $71.7 \%$ were females with a mean age of $46.28 \pm 9.57$ years and a mean body mass index of (BMI) of $28.03 \pm 5.6 \mathrm{~kg} / \mathrm{m}^{2}$. Comparisons of HP groups with baseline demographic and clinical characteristics of patients are shown in Table 1. There was no significant difference between the two groups in terms of age, sex, BMI, systolic and diastolic blood pressure, and smoking status.

The laboratory data of the patients in the HP groups are presented in Table 2. The native thiol and total thiol levels were significantly higher in the HP (+) group than in the HP (-) group ( $\mathrm{p}=0.005$ and $\mathrm{p}=0.027$, respectively) (Table 2 and Figure 1 and Figure2).

There was no significant difference between the groups in terms of the disulfide levels, disulfide/native thiol, disulfide/total thiol, and native thiol/total thiol ratios. The mean IMA value was 0.81 -absorbance unit (au) in the HP (+) group and 0.84 au in the HP (-) group, indicating no statistically significant

MDA level was $3.9 \mathrm{~mol} / \mathrm{L}$ in the HP (+) group and a slightly lower $3.8 \mathrm{~mol} / \mathrm{L}$ in the HP (-) group, although not statistically significant. 
Table 1: Comparisons of general characteristics in Helicobacter Pylori groups.

\begin{tabular}{|c|c|c|c|}
\hline Variable & $\mathrm{HP}(+)$ & HP (-) & $\mathrm{p}$ \\
\hline Age (years) ${ }^{\dagger}$ & $43.85 \pm 8.80$ & $48.81 \pm 9.85$ & 0.059 \\
\hline $\operatorname{Sex}(F / M)^{\ddagger}$ & $20(74.1) / 7(25.9)$ & $18(69.2) / 8(30.8)$ & 0.696 \\
\hline $\operatorname{BMI}\left(\mathrm{kg} / \mathrm{m}^{2}\right)^{q}$ & $27.34(19.53-46.07)$ & $26.72(17.58-52.79)$ & 0.838 \\
\hline Systolic BP $(\mathrm{mmHg})^{9}$ & $126.50(102-210)$ & $138(110-187)$ & 0.332 \\
\hline Diastolic BP $(\mathrm{mmHg})$ & $82.50(65-122)$ & $86(70-137)$ & 0.248 \\
\hline Smokers & $4(14.8)$ & $7(26.9)$ & 0.277 \\
\hline
\end{tabular}

${ }^{\dagger}:$ mean \pm standard deviation, ${ }^{*}: \mathrm{n}(\%),{ }^{\eta}$ : median (min-max).

HP: Helicobacter pylori; BMI: body mass index, BP: blood pressure.

Table 2. Comparisons of the laboratory results in Helicobacter Pylori groups.

\begin{tabular}{|c|c|c|c|}
\hline Variable & $\mathrm{HP}(+)(\mathrm{n}=27)$ & $\mathrm{HP}(-)(\mathrm{n}=26)$ & $\mathrm{P}$ \\
\hline Albumin $(\mathrm{g} / \mathrm{dL})^{\natural}$ & $4.30(2.80-5.20)$ & $4.10(1.70-5.30)$ & 0.161 \\
\hline $\operatorname{IMA}(\mathrm{AU})^{\Uparrow}$ & $0.81(0-0.97)$ & $0.84(0.61-0.96)$ & 0.388 \\
\hline IMA/Albumin $ף$ & $0.19(0-0.32)$ & $0.20(0.11-0.53)$ & 0.168 \\
\hline Native thiol $(\mathrm{mmol} / \mathrm{lt})^{\dagger}$ & $451.03 \pm 55.95$ & $407.03 \pm 52.19$ & 0.005 \\
\hline Total thiol (mmol/lt) & $493.20(411.80-675.20)$ & $456.40(344.90-548)$ & 0.027 \\
\hline Disulfide $(\mathrm{mmol} / \mathrm{lt})$ & $21.95(5.30-37.25)$ & $22.63(14.40-41.25)$ & 0.612 \\
\hline SS/native thiol $(\%)^{\pi}$ & $4.95(0.90-7.33)$ & $5.59(3.45-10.72)$ & 0.068 \\
\hline SS/total thiol $(\%)^{q}$ & $4.50(0.90-7.33)$ & $5.03(3.23-8.83)$ & 0.070 \\
\hline Native/total thiol (\%) & $90.99(85.35-98.21)$ & $89.95(82.34-93.54)$ & 0.070 \\
\hline $\operatorname{FRAP}(\mu \mathrm{mol} / \mathrm{L}) \pi$ & $0.94(0.64-2.07)$ & $1.10(0.61-1.87)$ & 0.059 \\
\hline Malondialdehyde $(\mu \mathrm{mol} / \mathrm{L})^{\dagger}$ & $3.9 \pm 1.0$ & $3.8 \pm 1.0$ & 0.610 \\
\hline
\end{tabular}

${ }^{\dagger}:$ mean \pm standard deviation, $"$ : median (min-max).

HP: Helicobacter pylori, IMA: ischemia-modified albumin, FRAP: ferric reducing ability of plasma, AU: absorbance unit, SS: disulfide.

\section{Discussion}

In this study, the possible relationship between HP and thiol-disulfide homeostasis was evaluated. The native thiol and total thiol levels were significantly higher in the HP (+) group than in the HP (-) group. No significant differences between the groups were observed in FRAP, IMA, MDA and disulphide levels. The FRAP levels was lower in the HP (+) group, but the difference between the two groups was not statistically significant.

A study conducted in humans showed higher MDA levels in the gastric mucosa of HP-infected patients, compared to healthy tissues, and that MDA levels returned to normal after HP eradication [8]. Remarkably increased serum MDA, catalase, and superoxide dismutase levels were demonstrated in patients with HP infection [14], although, in the present study, we found no statistically significant difference between the MDA levels of the two groups. IMA increases in oxidative stress conditions associated with ischemia and is considered a biomarker of oxidative stress, which is, in turn, associated with chronic kidney disease, hypercholesterolemia, and type 2 diabetes mellitus [1517]. In the present study, we found no statistically significant difference in IMA and albumin levels or IMA/albumin ratios.

FRAP is one of the most widely used technique for the measurement of total antioxidant capacity [7]. Several studies have reported total oxidant status, total antioxidant capacity, and oxidative stress index to be significantly higher in HP-infected patients than in non-HP infected patients [18]. However, in our study, we found no statistically significant difference between the FRAP levels of the two groups.

Interestingly, contrary to expectations, a comparison of the native thiol and total thiol parameters of the HP (+) and HP () groups revealed significantly higher levels in the HP (+) group in our study. Thiols are considered to be the main antioxidant buffer, and play an important role in protecting against the detrimental effects of ROS [19]. Proteins containing thiol groups act as an antioxidant buffer, but are also involved in the regulation of the redox system [20]. Thiols are both antioxidant and pro-oxidant molecules, and although thiols are mostly considered antioxidant molecules, they may act as pro-oxidant molecules, depending on the physical status of the organism [21, 22]. The level of oxidative stress in an organism is the determinant of the behavior of thiols, and this is maintained with a dynamic balance in the body. Naja et al. has found no significant difference in the plasma thiol level in HP infected patients compared with controls [23]. Baykan et al. reported that there was no difference between the total thiol, native thiol, disulphide/native thiol and dissulphide/total thiol ratios of the HP (+) patients and control group [24]. They claimed severity of inflammation affected their results. In the present study, disulfide levels, disulfide/native thiol ratio, and disulfide/total thiol ratio were found to be similar between the two groups, suggesting that TDH is not impaired in the HP (+) group.

Nonetheless, there are some limitations to the present study. First, our sample size was relatively small. Second, it was conducted in a single center. Therefore, the results cannot be generalized to other populations or settings. Smokers are another limitation of the study since smoking may interfere with the results. We recommend further large-scale, multi-center, prospective studies to establish a definitive conclusion.

In conclusion, we evaluated oxidative status of HP patients in several different methods. Among them, only elevated native thiol and total thiol levels were found in HP-induced gastritis. There is a need for further studies involving a larger number of patients and a subgroup analysis to examine whether elevated serum thiol-disulfide levels in HP infection suggest an antioxidant or pro-oxidant status. 
a

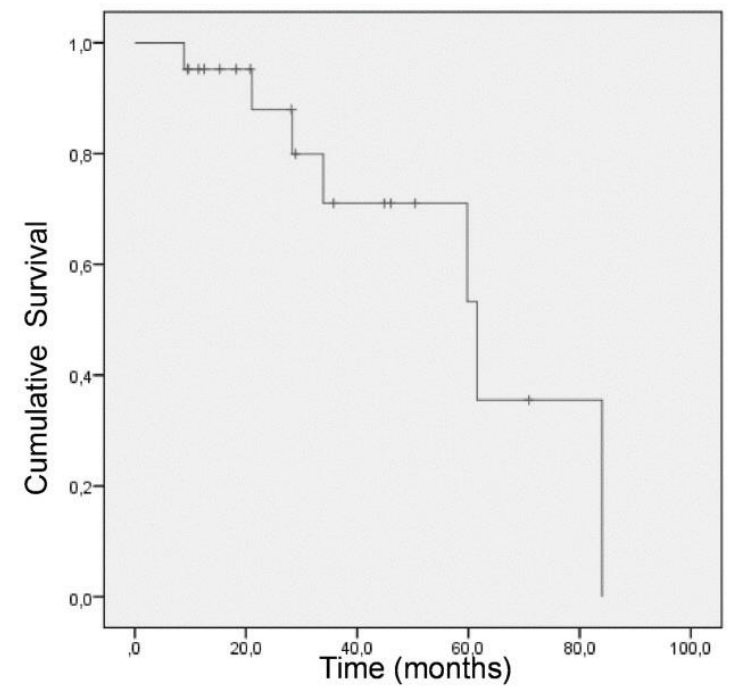

b Progression-free

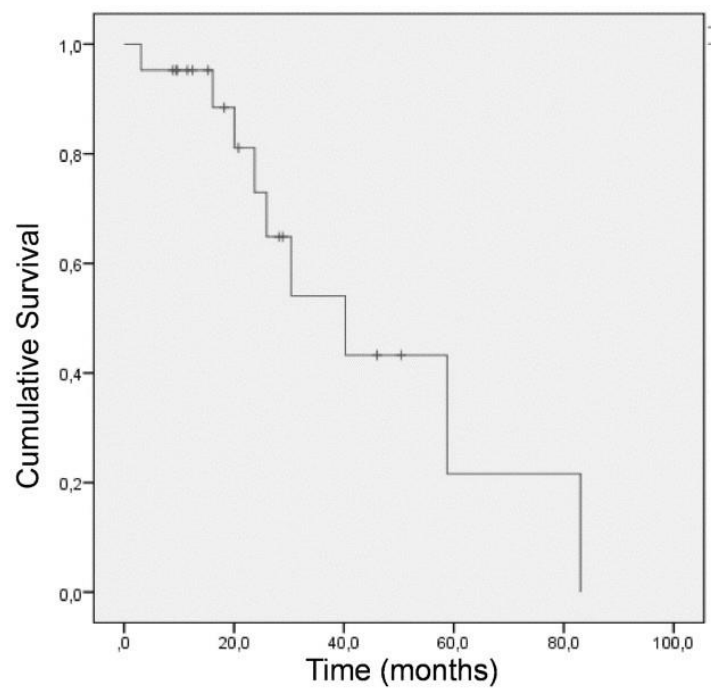

Figure1. Relationship between native thiol (mmol/lt) and Helicobacter pylori. HP: Helicobacter pylori.
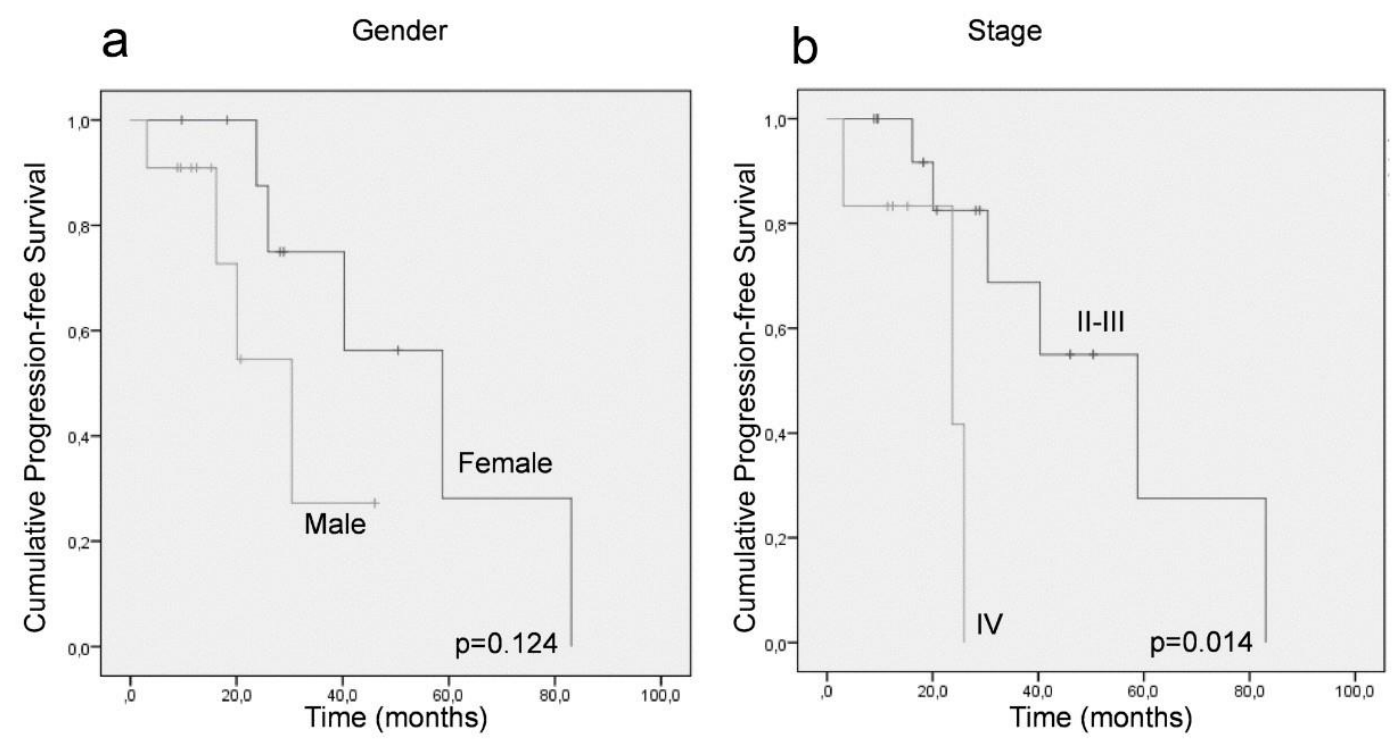

Figure2. Relationship between total thiol (mmol/lt) and Helicobacter pylori. HP: Helicobacter pylori.

\section{References}

1. Wroblewski LE, Peek RM Jr, Wilson KT. Helicobacter pylori and gastric cancer: factors that modulate disease risk. Clin Microbiol Rev. 2010;23:713-39.

2. Jiang, J, Chen Y, Shi, J, Song C, Zhang J, Wang, K. Population attributable burden of Helicobacter pylorirelated gastric cancer, coronary heart disease, and ischemic stroke in China. Eur J Clin Microbiol Infect Dis. 2017;36:199-212.

3. McColl KE. Helicobacter pylori infection. N Engl J Med. 2010, 29;362:1597-604.

4. Helicobacter and Cancer Collaborative Group. Gastric cancer and Helicobacter pylori: a combined analysis of 12 case control studies nested within prospective cohorts. Gut, 2001,49: 347-53.

5. Butcher LD, den Hartog G, Ernst PB, Crowe SE. Oxidative Stress Resulting From Helicobacter pyloriInfection Contributes to Gastric Carcinogenesis. Cell Mol Gastroenterol Hepatol. 2017,20;3:316-22.

6. Bar-Or D, Lau E, Rao N, Bampos N, Winkler JV, Curtis CG. Reduction in the cobalt binding capacity of human albumin with myocardial ischemia. Ann Emerg Med, 1999, 34:S56.

7. Ustundag Y, Huysal K, Kahvecioglu S, Demirci H, Yavuz $\mathrm{S}$, Sambel M, et al. Establishing reference values and evaluation of an in-house ferric reducing antioxidant power (FRAP) colorimetric assay in microplates. Eur Res J, 2016;2:126-31. 
8. Drake IM, Mapstone NP, Schorah CJ, White KL, Chalmers DM, Dixon MF, et al. Reactive oxygen species activity and lipid peroxidation in Helicobacter pylori associated gastritis: relation to gastric mucosal ascorbic acid concentrations and effect of $\mathrm{H}$ pylori eradication. Gut. 1998;42:768-71.

9. Hansen RE, Roth D, Winther JR. Quantifying the global cellular thiol-disulfide status. Proc Natl Acad Sci U S A. 2009; 106:422-7.

10. Amagase K, Nakamura E, Endo T, Hayashi S, Hasumura M, Uneyama H et al. New Frontiers in Gut Nutrient Sensor Research: Prophylactic Effect of Glutamine Against Helicobacter pylori-Induced Gastric Diseases in Mongolian Gerbils. J Pharmacol Sci. 2010;112:25-32.

11. Handa O, Naito Y, Yoshikawa T. Helicobacter pylori: a ROS-inducing bacterial species in the stomach. Inflamm Res. 2010;59:997-1003.

12. Aslan M, Nazligul Y, Horoz M, Bolukbas C, Bolukbas FF, Aksoy N, et al. Serum prolidase activity and oxidative status in Helicobacter pylori infection. Clin Biochem. 2007;40:37-40.

13. Erel O, Neselioglu, S. A novel and automated assay for thiol/disulphide homeostasis. Clin Biochem. 2014;47:32632.

14. Hagag AA, Amin SM, El-Fiky RB, El-Sayad ME. Study of serum levels of some oxidative stress markers in children with Helicobacter pylori infection. Infect Disord Drug Targets. 2018;18:52-9.

15. Cichota LC, Moresco RN, Duarte MM, da Silva JE. Evaluation of ischemia-modified albumin in anemia associated to chronic kidney disease. J Clin Lab Anal. 2008;22:1-5.

16. Duarte MM, Rocha JB, Moresco RN, Duarte T, Da Cruz IB, Loro VL, et al. Association between ischemia-modified albumin, lipids and inflammation biomarkers in patients with hypercholesterolemia. Clin Biochem. 2009;42:666-71.

17. Kaefer M, Piva SJ, De Carvalho JA, Da Silva DB, Becker AM, Coelho AC, et al. Association between ischemia modified albumin, inflammation and hyperglycemia in type 2 diabetes mellitus. Clin Biochem. 2010;43:450-4.

18. Başyiğit S, Akbaş H, Süleymanlar İ, Kemaloğlu D, Koç S, Süleymanlar G. The assessment of carotid intima-media thickness, lipid profiles and oxidative stress markers in Helicobacter pylori-positive subjects. Turk J Gastroenterol. 2012;23:646-51.

19. Halliwell B. Free radicals, antioxidants, and human disease: curiosity, cause, or consequence? Lancet. 1994, 10;344:721-4.

20. Ghezzi P, Bonetto V, Fratelli M. Thiol-disulfide balance: from the concept of oxidative stress to that of redox regulation. Antioxid Redox Signal. 2005;7:964-72.

21. Atmaca G. Antioxidant effects of sulfur-containing amino acids. Yonsei Med J. 2004;45:776-88.

22. Lynch SM, Campione AL, Moore MK. Plasma thiols inhibit hemin-dependent oxidation of human low-density lipoprotein. Biochim Biophys Acta. 2000;1485:11-22.

23. Naja F, Kreiger N, McKeown Eyssen G, Allard J. Bioavailability of vitamins $\mathrm{E}$ and C: does H. pylori infection play a role? Ann Nutr Metab. 2010;56:253-9.

24. Baykan AR, Biçer C, Gerçeker E, Erel Ö, Cerrah S, Albayrak B, et al. Thiol/disulphide homeostasis in Helicobacter pylori infected patients. European Res J. 2019;5:948-56. 